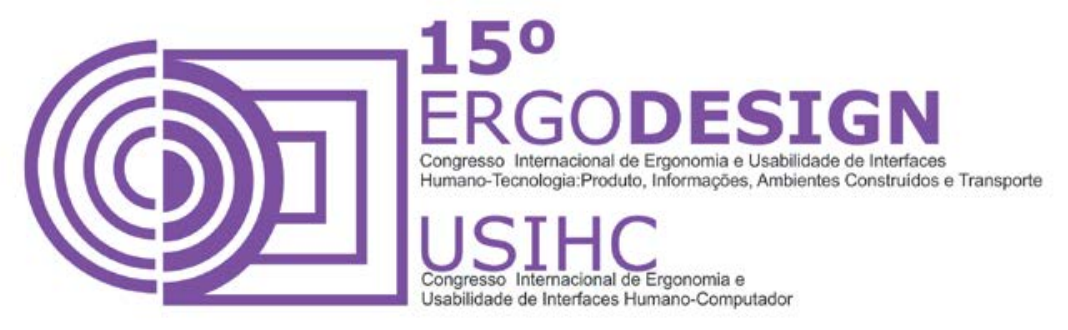

\title{
SUPORTE POSTURAL BIOCINÉTICO PARA TRATAMENTO FISIOTERAPÊUTICO EM CRIANÇAS DE 2 A 8 ANOS, QUE SOFREM DE DOENÇAS NEUROMUSCULARES E ALTERAÇÕES POSTURAIS
}

\author{
SUPPORT BIOKINETIC POSTURAL TO PHYSIOTHERAPEUTIC \\ TREATMENT IN KIDS FROM 2 TO 8 YEARS OLD, WHO SUFFER FROM \\ NEUROMUSCULAR DISEASES AND POSTURAL ALTERATIONS.
}

\author{
SILVA, Ana Beatriz Rossi (1); \\ PACCOLA, Sileide Aparecida de Oliveira (2); \\ (1) Universidade Sagrado Coração, Bacharel em Design \\ e-mail: abeatrizrossis@gmail.com \\ (2) Universidade Sagrado Coração, Doutora \\ e-mail: sileide.paccola@usc.br
}

\begin{abstract}
RESUMO
As doenças neuromusculares compreendem um universo de diferentes patologias que afetam a unidade motora do corpo, tendo em comum a falta de força muscular, o que torna necessário aos doentes apoios, adaptações e/ou ajudas técnicas. Este trabalho teve como foco desenvolver uma alternativa inovadora de design para a roupa biocinética, utilizada no tratamento fisioterapêutico em crianças de 2 a 8 anos, que sofrem de doenças neuromusculares e alterações posturais. O resultado apoia-se, sobretudo, nas funções estética e simbólica do produto, a fim de introduzir ludicidade atrativa ao público alvo, fazendo com que as crianças, que têm necessidade desse produto, queiram usá-lo.
\end{abstract}

Palavras chave: Design em saúde, suporte postural, ludicidade, design universal.

\begin{abstract}
Neuromuscular diseases comprise a universe of different pathologies that affect the motor unit of the body, having in common the lack of muscle strength, which makes it necessary to support patients , adaptations and / or technical aids. This work focused on developing a design innovative alternative to the biokinetics clothing, used in physical therapy in children 2-8 years old, suffering from neuromuscular disorders and postural changes. The result relies mostly on aesthetic and symbolic functions of the product, in order to introduce attractive playfulness to the target audience, making children who need this product, please use $i$.
\end{abstract}




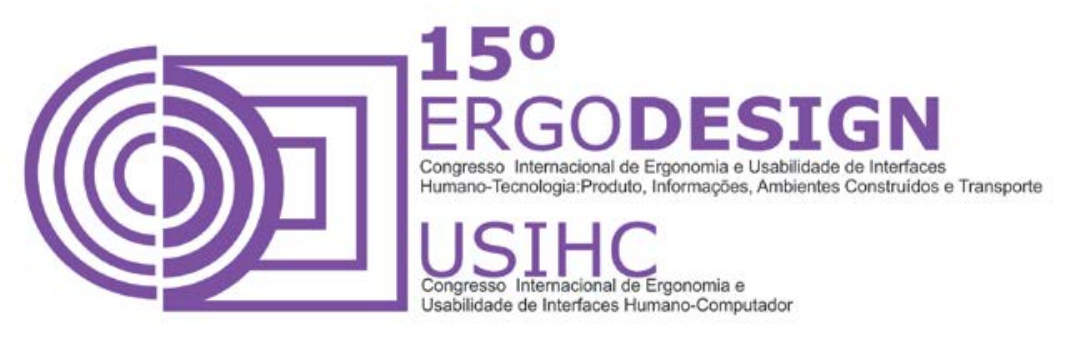

Keywords: Health Design, postural support, playfulness, universal design.

\section{INTRODUÇÂO}

[...] "As deficiências neuromotoras frequentemente culminam em um atraso no desenvolvimento neuropsicomotor, em virtude de uma lesão no sistema nervoso central, que provoca comprometimentos na área motora, sensorial e/ou cognitiva, implicando em alterações de tônus muscular, qualidade de movimento, percepções e capacidade de apreender e interpretar os estímulos ambientais". (ALVES DE OLIVEIRA, 2008).

Segundo Ubaldo (2002), o aumento do tônus muscular é fator responsável por levar o paciente a adotar posturas anormais com movimentos restritos, contração inadequada, limitação funcional em adotando determinadas posturas, criando assim um desequilíbrio muscular.

Estudos têm mostrado que além dos métodos utilizados em terapias é necessário dispositivo de manutenção e de prevenção de deformidades, justificando a importância dos trajes e suportes para prevenir maiores deformidades e para suporte ao usuário, cujos principais objetivos, segundo Suit (2014), estão relacionados ao aumento da variedade dos movimentos ativos, aumento da força e da resistência muscular e ao controle dos grupos musculares que acabaram de ganhar força, permitindo que a criança melhore suas habilidades.

Assim, a partir das pesquisas realizadas, pôde-se perceber a necessidade de se aprimorar 0 traje que auxilia a reabilitação de crianças com deficiência neuromotora, considerando não apenas as características pertinentes a essa deficiência como também as características do contexto onde cada possível usuário está inserido.

Esse direcionamento do projeto ocorreu por meio dos requisitos levantados com foco em encontrar a melhor alternativa a ser desenvolvida. $O$ conjunto de requisitos foi constituído pelo seguintes aspectos: ergonômico, fisioterapêutico, de material, estético, simbólico, de fabricação/custo e da biônica aplicada ao design.

O estudo em questão teve como objetivo adequar a roupa biocinética, adotado atualmente para tratamento fisioterapêutico de crianças de 2 a 8 anos, segundo os requisitos de projeto, tornando-o, essencialmente, viável a realidade econômica popular, além de melhorar a sua forma de uso e torná-lo atraente ao seu público destinado.

\section{JUSTIFICATIVA}

As discussões em torno da roupa atingem também outros campos de estudo, entre eles os específicos aos aspectos posturais, a influência da ergonomia e também a história do Design.

Segundo Paschoarelli (1997), a relação homem X tecnologia, pode ser compreendida pelas disciplinas científicas do Design e da Ergonomia, em que a primeira determina métodos para desenvolvimento de produtos e a segunda ajusta estes produtos às necessidades e às capacidades psicofísicas humanas. Sabemos que cada vez mais a tecnologia vem proporcionando ao homem grandes inovações em todas as áreas, sendo a saúde uma delas. 


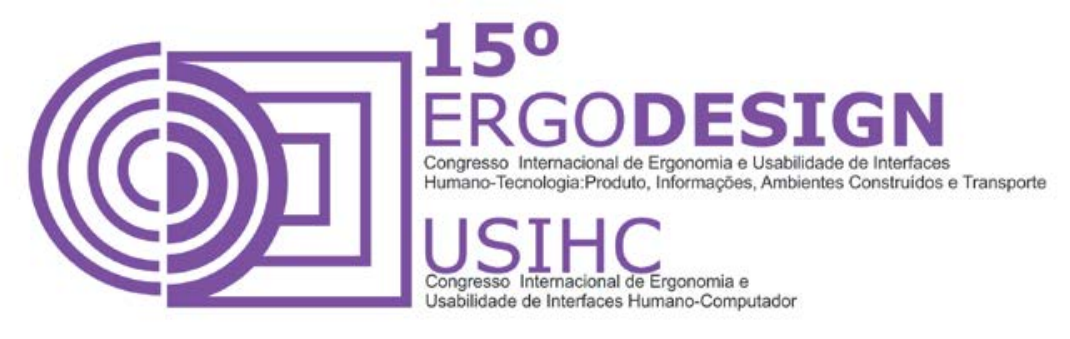

Utilizada por alguns profissionais da área da fisioterapia, a roupa biocinética é uma aliada na reabilitação de crianças com lesões neuromusculares e alterações posturais, ajudando cada criança de acordo com sua necessidade.

Contudo, há alguns fatores que são impeditivos para que o produto tenha sua aplicação ampliada à população. Dentre eles, os mais significantes são o material e o custo, em virtude do tecido empregado na fabricação da roupa ter tecnologia específica, elevando significativamente o seu custo para o usuário final. Estes fatores estão extremamente vinculados à função do produto. Ou seja, o material utilizado gera alto custo na sua produção, que é repassado para o usuário, porém traz nas suas características físicas as condições favoráveis para a execução do tratamento. Os trajes atuais apresentam características que podem aparecer juntas ou separadas, mas que de forma geral concorrem para a dificuldade de aquisição da parcela menos favorecida da população.

\section{OBJETIVOS}

\subsection{Objetivos gerais}

Desenvolver solução inovadora para a roupa biocinética empregada no tratamento fisioterapêutico de crianças com idade entre 2 a 8 anos, adotando materiais e características morfológicas estruturais que viabilizem o seu custo de fabricação, a fim de resultar num produto acessível a um público mais expressivo de usuários.

\subsection{Objetivos específicos}

- $\quad$ Avaliar marcas e modelos disponíveis no mercado.

- $\quad$ Analisar os pontos positivos a serem trabalhados e os negativos a serem melhorados.

- $\quad$ Comparar eficácia, materiais e custos.

- $\quad$ Fazer o levantamento de requisitos para o produto.

- Diagnosticar as necessidades para a melhoria do traje.

- Desenvolver um suporte postural.

\section{DESENVOLVIMENTO}

A coleta de dados foi realizada através do levantamento bibliográfico sobre o assunto, nas bases de dados disponíveis na Universidade Sagrado Coração, livros, artigos e dados da internet.

A partir da especificação dos requisitos de projeto, foram definidos os materiais que poderiam ser utilizados na produção de uma roupa para crianças portadoras de doenças neuromusculares, além dos processos utilizados. A análise de similares foi realizada a partir de critérios: ergonômico, fisioterapêutico, materiais, estético-simbólico, fabricação/custo e biônica. 


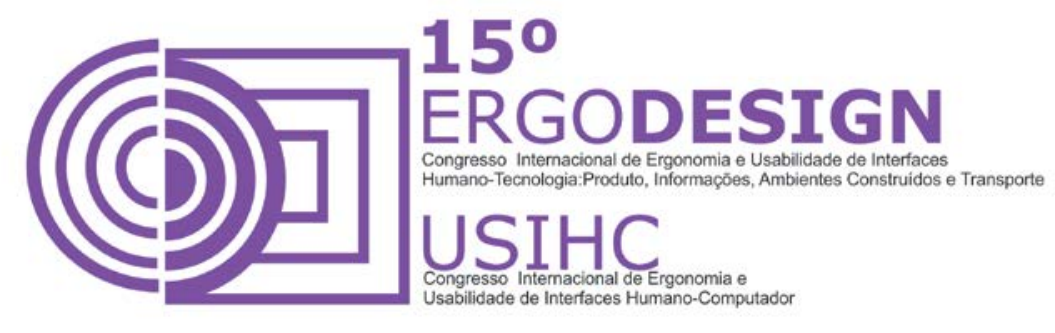

Para geração de alternativas foram realizados sketches que possibilitaram a geração de propostas que chegassem a uma solução mais adequada, segundo os requisitos.

\subsection{Caracterização do público alvo}

Associado as questões anteriormente descritas, observam-se também as características principais do público alvo a serem estudadas, as crianças que sofrem de doenças neuromusculares e alterações posturais, com idade de 2 a 8 anos.

CRONEY (1978) e IIDA (1990) observam que os produtos devem ser adaptados ao público alvo, com respeito as suas medidas antropométricas e certas necessidades de cada faixa etária. Ou seja, produtos infantis não devem ser em escala proporcional a dos adultos. Como a população infantil está sempre em constante crescimento, o fato de sua morfologia e dimensões mudarem, faz-se a necessidade de adequações antropométrica.

Com a criança com alguma deficiência isso não é diferente. Mesmo tendo alguns atrasos no seu desenvolvimento cognitivo e motor, elas também se envolvem por atividades lúdicas no seu dia a dia, muitas vezes até mais que as outras crianças (MAFRA, 2008).

Para melhor entender e relacionar a moda, design e a saúde - fisioterapia, é necessário um breve histórico com foco no vestuário de modo geral. Conforme é analisado por Lurie (1997), na Idade Média as roupas infantis eram a versão reduzida das roupas adultas. Estas usavam roupas bufantes, cujo material empregado na época era muito desconfortável para as crianças.

Podemos ver isso até mesmo nas pinturas de crianças do século XVIII, quando o que distinguia tanto os trajes de meninos como os de meninas, era apenas um tipo de guia para ajudar a criança a caminhar, e que é descrito por Ariès (1986) como: duas fitas largas, presas ao vestido atrás dos ombros, pendentes nas costas, as quais se tornaram signos da infância.

Como mostra o estudo de Santana (2011), com o passar do tempo às roupas passam por modificações, como os vestidos de renda utilizados por meninos e meninas, roupas no estilo marinheiro, entre outras, até chegar ao que temos atualmente para o vestuário infantil. É percebido que a moda contribui para a educação das crianças, beneficiando-a ou não. Evidencia-se essa questão em 1950, quando, segundo Postman (1999), este foi o período no qual se instala a televisão nos lares, destruindo a linha divisória entre infância e idade adulta.

Assim, as crianças passam a ser consumidoras, conforme escrevem Bezerra e Waechter (2008), sendo submetidas às publicidades lúdicas, onde as empresas conquistam o pequeno público encantando-os com mensagens visuais destinadas a eles, com cores, texturas e forma diferenciadas e direcionadas às crianças.

Segundo Piaget (1996), a aprendizagem está relacionada ao desenvolvimento da criança, deste modo, suas escolhas são feitas e modificadas de acordo com seu estágio de desenvolvimento. Conforme este autor, o estágio do público alvo em questão é o período pré-operacional, que se caracteriza, principalmente pela interiorização de pensamentos e reflexos. Nessa criança a aceitação das coisas só acontece quando se tem uma explicação (é a fase dos "por quês"). Já age por simulação e imitação, tem percepção global, sem discriminar detalhes e deixa se levar pela aparência. 


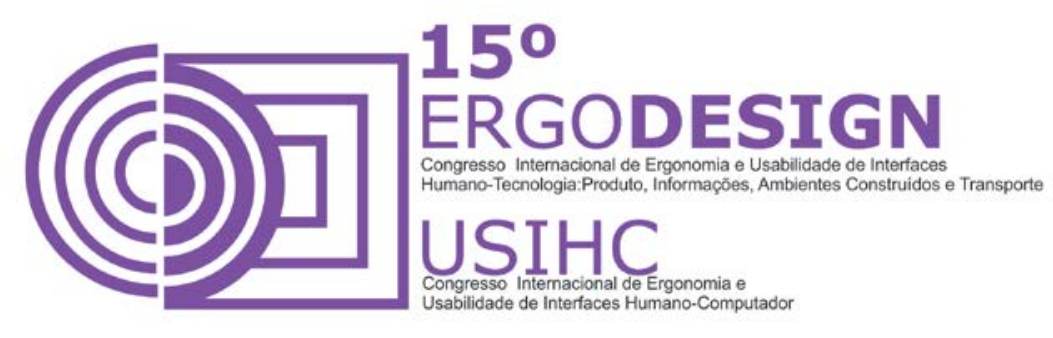

Considerando a questão da fase em que se encontra o público alvo, crianças de 2 a 8 anos, é um período onde a criança se deixa levar pela aparência das coisas (PIAGET, 1996), faz-se a valorização para a apropriação da prática lúdica, pois tal atividade propicia a expressão do imaginário, a aquisição de regras e a apropriação do conhecimento. O lúdico, para Piaget (1975), possibilita que a criança com deficiência intelectual se torne cada vez mais autônoma, melhorando a autoestima e a consciência corporal.

Para melhor entender, lúdico vem de ludens, no latim, e sua essência se baseia no divertimento, prazer, agrado e alegria, segundo Huizinga (1971). Então, [...] "objetos, sons, movimentos, espaços, cores, figuras, pessoas, tudo pode virar brinquedo através de um processo de interação em que estes recursos funcionam como elementos que nutrem a atividade lúdica". (CUNHA, 2007). Apesar de o lúdico ter várias referências, para as crianças, ele é fator determinante para a captura da atenção da criança. Além de divertir, ele ainda educa, interfere diretamente na fantasia, resultando no encantamento. (FREITAS e BORGES, 2006, p.16).

Por meio da pesquisa feita por Heirich e Troncoso (2014) com base em coleções de marcas de roupas infantis, foi possível a criação de um painel de elementos lúdicos mais utilizados nas roupas infantis, como mostra a Figura01. Com base neste levantamento puderam realizar uma entrevista interativa com crianças, na qual os resultados obtidos foram extremamente importantes para análise de elementos lúdicos no vestuário infantil.

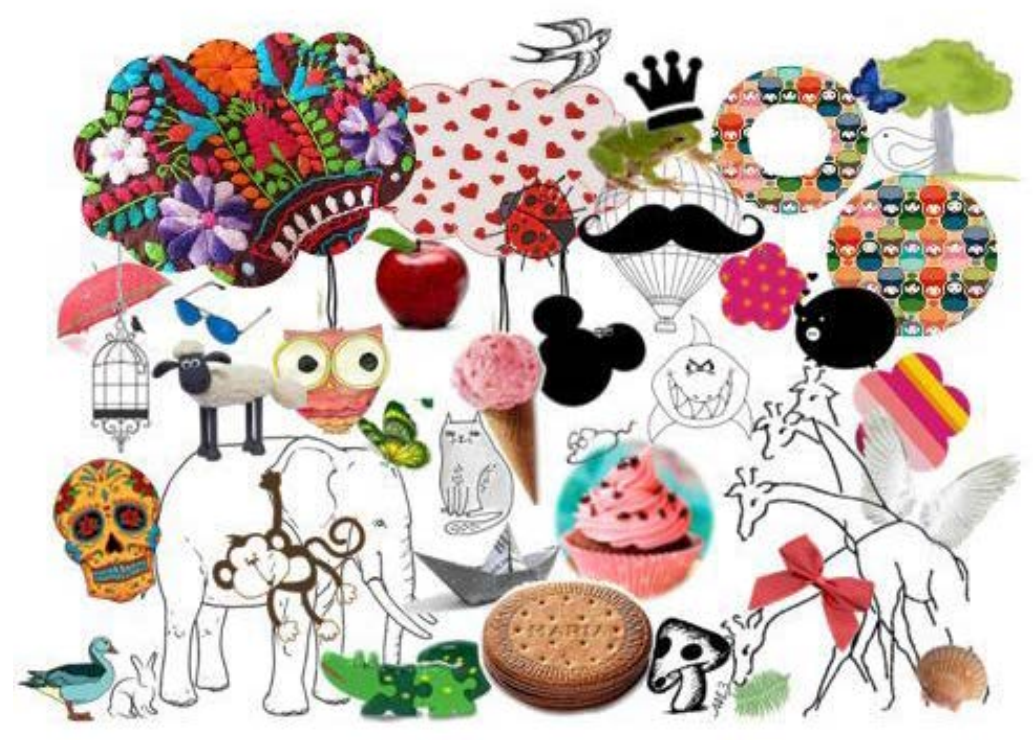

Figura 01: Painel com os elementos lúdicos da pesquisa. Fonte: Heirich e Troncoso (2014).

Esta entrevista interativa foi elaborada pensando na interação da criança, estimulando o raciocínio e a criatividade. Para isso, os elementos levantados no painel de elementos lúdicos 


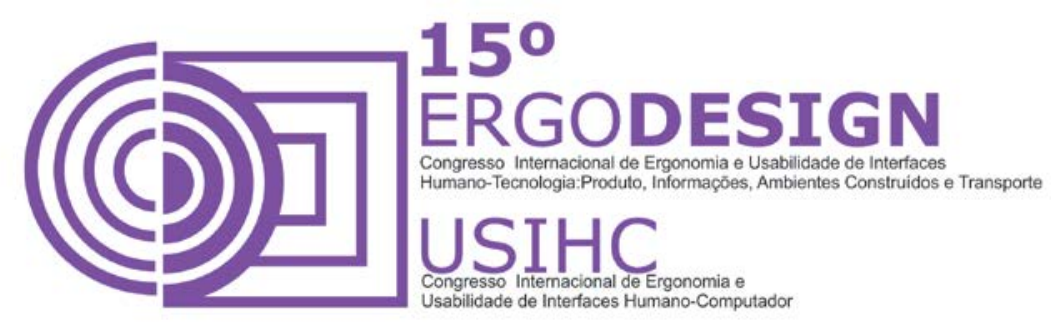

foram reproduzidos em feltro para que as crianças pudessem escolher e aplicar em bonecos também de feltro, como ilustrado na figura 02.

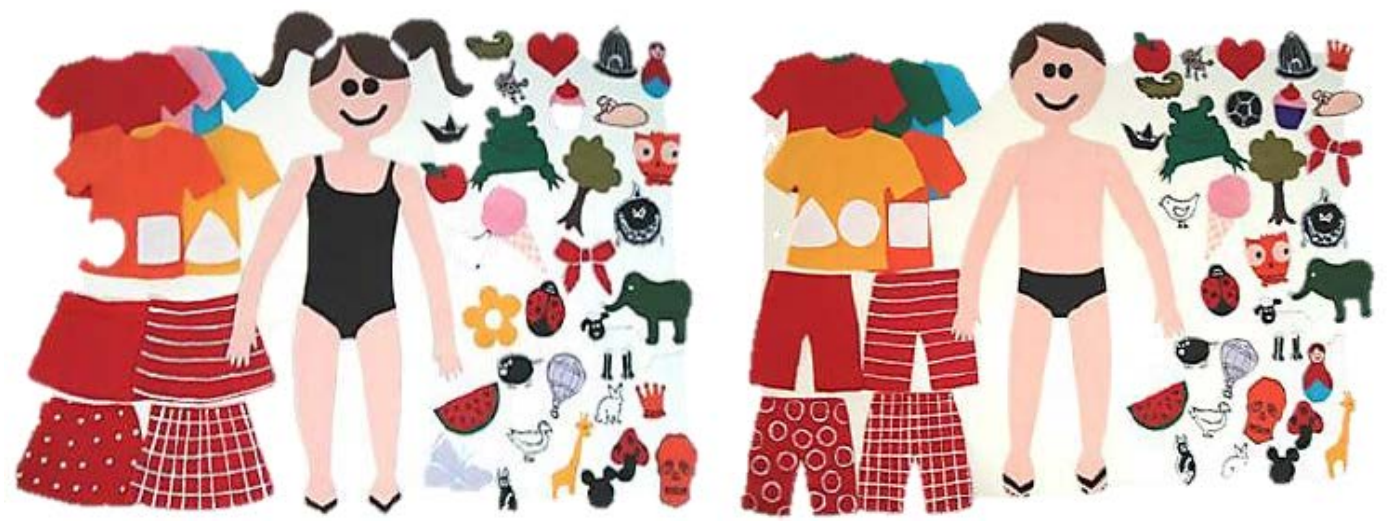

Figura 02: Bonecos, cores e elementos em feltro para a aplicação do questionário. Fonte: Heirich e Troncoso (2014).

Nos resultados destacam-se que as crianças de 2 a 5 anos escolhiam os elementos que agradavam os olhos, já as crianças de 6 a 10 anos escolhiam os quais se identificavam, e que simbolizavam algo para eles. Além disso, para as crianças de menor idade preferem a cor vermelha, forma redondas e elementos relacionados à natureza e animais. Já as crianças com 5 anos ou mais fazem suas escolhas com relação a algum alimento (HEIRICH; TRONCOSO, 2014).

Ainda de acordo com a pesquisa de Heirich e Troncoso (2014), foi identificado que entre as cores preferidas entre as meninas foi o rosa e entre os meninos, o vermelho e azul. Já as formas, em ambos os sexos, foi escolhido o círculo, porém a textura foi o poá (bolinhas) entre meninas, o liso e xadrez entre os meninos. Verificou-se entre todos os elementos a preferência das meninas por laço, coração e borboleta, e caveira, bola e tubarão para os meninos.

\subsection{Requisitos do projeto}

Diante das considerações e dos dados levantados até esse momento, para que o produto em questão, roupa biocinética, tenha um bom design e seja ergonomicamente correta, perante a necessidade do público alvo, é necessário que esta atenda aos seguintes requisitos:

\subsubsection{Ergonomia}

A ergonomia deve aperfeiçoar o produto a fim de deixá-lo mais compatível com as necessidades, as habilidades e as limitações das crianças com doença neuromusculares, tendo sempre como base para essa otimização dos parâmetros e dimensões do público alvo, condicionando a fácil colocação da mesma, para que não haja incômodo por parte do paciente. Deve também ser adequada ao perfil antropométrico do público alvo. 


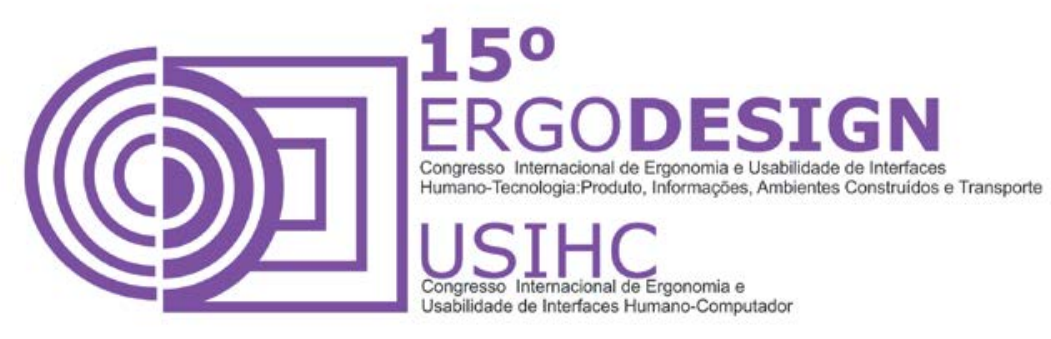

\subsubsection{Fisioterapêuticos}

A partir dos dados levantados o traje deve beneficiar tanto o publico alvo, crianças de 2 a 8 anos, como também os cuidadores, os pais, terapeutas, e fisioterapeutas. Como já dito, a roupa deve ser as "mãos extras" do fisioterapeuta nas atividades do dia a dia. (THERATOGS...,c2014).

Além disso, a mesma deve ajudar no desenvolvimento ósseo e articular em bebês e crianças; na consciência corporal e estabilidade postural; no alinhamento articular funcional e em repouso. Também deve beneficiar na terapia suplementando e reforçando os treinamentos neuromotores, aumentando a probabilidade de melhores resultados terapêuticos, com um sistema de terapia personalizado e fácil de usar, e cumprindo as metas/objetivos do tratamento, sem forçar o paciente. (THERATOGS...,c2014).

A roupa deve favorecer os terapeutas e cuidadores, por meio dos ajustes das posturas. Para melhor contextualizar, segundo Moore (2011), ao dividir nosso corpo ao meio temos um eixo, onde um lado convencionou-se como direito e o outro esquerdo, no qual cada movimento realizado tem uma nomenclatura básica. São elas:

- Flexão: diminuição do ângulo da articulação;

- Extensão: aumento do ângulo de flexão ou movimento contrário à flexão;

- Abdução: afastamento da articulação do eixo;

- Adução: aproximação da articulação do eixo;

- Rotação: movimento realizado em torno do próprio eixo da articulação.

\subsubsection{Material}

Como o traje deve ser utilizado em longo período pelo paciente, ele deve apresentar flexibilidade e condições de conforto, também em períodos com temperaturas mais altas no ano, pois os trajes atuais empregam tecidos que possuem alta densidade e por isso causam elevado desconforto térmico.

\subsubsection{Estética}

Baseado nas pesquisas realizadas para produção de roupas para o público infantil e na importância dos elementos lúdicos, para a atração das crianças no uso das mesmas, quanto a sua superfície, é necessário que o traje também tenha atrativos lúdicos tais como cores, estampas e texturas, familiares ao repertório infantil, que auxiliem também na aceitação e no sentimento de bem estar das crianças. Quanto a sua estrutura formal deve-se reduzir a quantidade de tecido utilizado, a partir de um novo desenho para a produção. A redução do material empregado ocasionará a redução do custo de produção e o aumento da viabilidade do produto.

\subsubsection{Fabricaçãol custo}




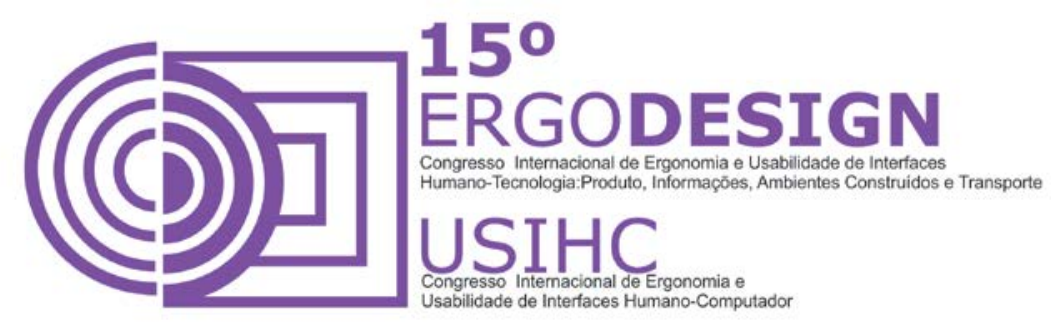

Um dos itens primordiais para a realização deste trabalho é deixar o produto economicamente acessível, pois os produtos que se encontram ofertados no mercado, cujas funções são semelhantes as esperadas neste projeto, possuem alto custo, restringindo-os aos usuários. Porém o "barateamento" dos produtos depende também acesso dos requisitos apresentados anteriormente, assim como uma melhor forma de fabricação, sem que esteja interfira na qualidade do produto final.

\subsubsection{Biônica com a aplicação em design}

A biônica tem como base a natureza, utilizando-se do rico terreno de soluções para problemas comparáveis aos do homem: estrutura; locomoção; coordenação; emissão, transmissão das informações, entre outros. Com base nisso, para a melhor solução do problema será aplicado a biônica ao produto.

\section{RESULTADOS}

Com base nas informações obtidas pelas pesquisas e análises, e conforme os requisitos necessários foram desenvolvidos oito alternativas, juntamente com a fisioterapeuta, observouse que a melhor ideia com funções mais eficientes aos portadores de doenças neuromusculares é a mostrada na figura 03. Pode ser utilizado para todos os pacientes, onde 0 terapeuta selecionará o melhor uso, sendo ele o de flexão ou extensão muscular.
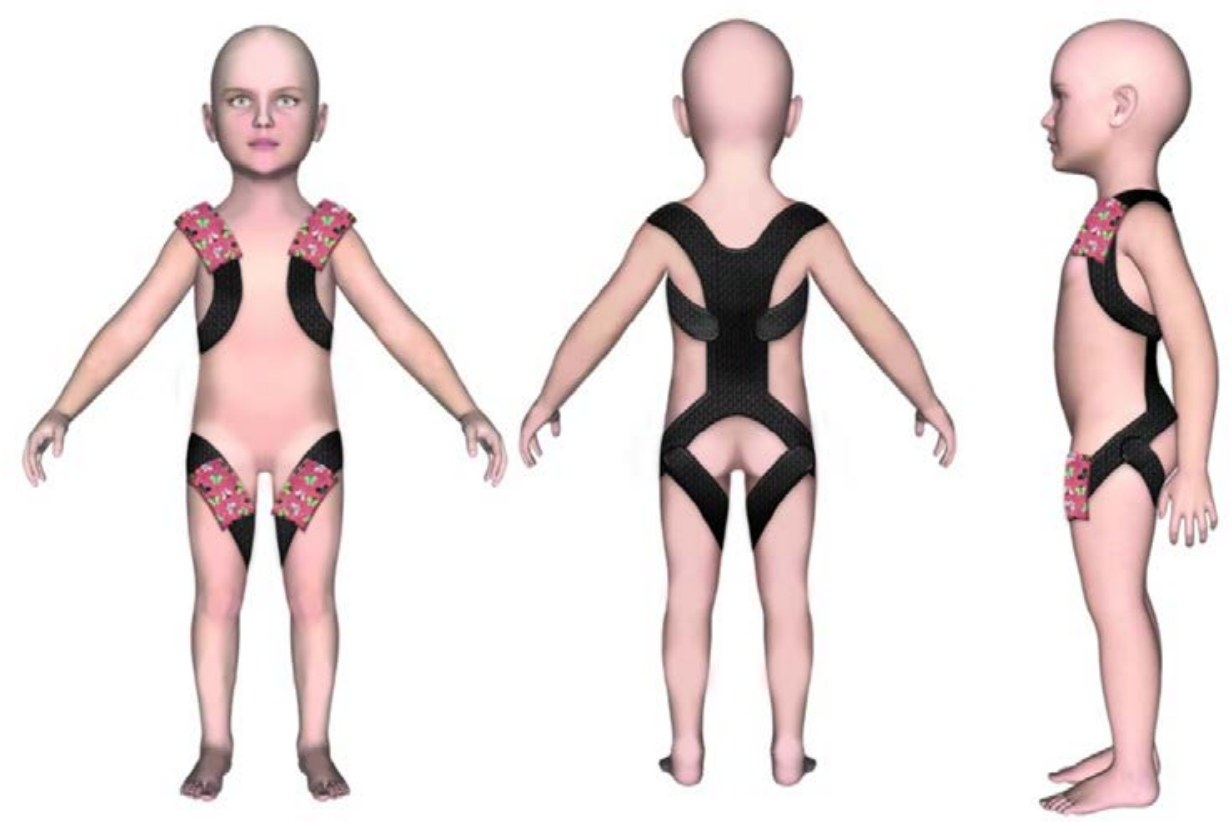

Figura 03: Ilustração do produto final. Fonte: Elaborado pelo autor. 


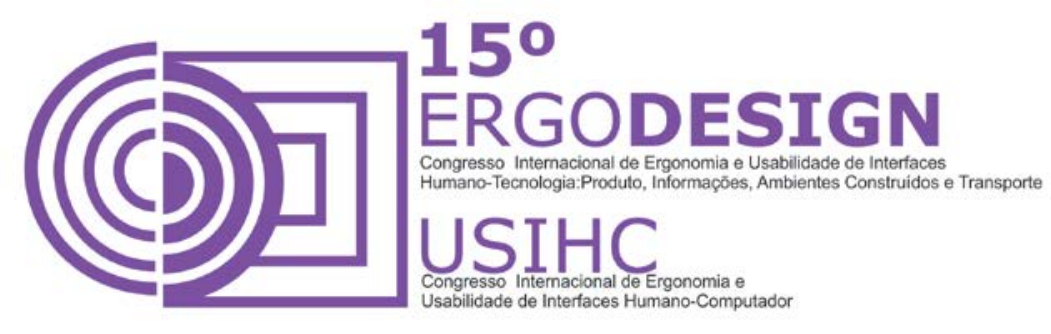

Baseada na biônica da borboleta, o apoio central da roupa estabiliza a coluna, mas também exige do paciente o controle, para que, mesmo com o uso da roupa, os músculos ainda continuem trabalhando. Já o apoio da parte inferior da roupa faz com que o membro inferior fique posicionado na rotação adequada, melhorando o equilíbrio e o posicionamento do paciente em pé, sentado ou até mesmo deitado, pois em posição de relaxamento o paciente não entrará nos padrões posturais causados por sua doença. O apoio superior da roupa posiciona a coluna torácica e ombros, fundamentais para que a criança possa realizar suas atividades de vida diária e tenha equilíbrio para manter em postura.

Não se pode esquecer de observar o paciente como um todo, e que além do apoio central que a roupa oferece, deve ser utilizado também as bandagens para que todos os músculos, inclusive os que não têm o apoio da roupa, possam trabalhar juntos para uma melhor postura. Pois, como cada paciente possui problemas específicos, a bandagem vai complementar a utilização da roupa.

Além disso, o fato da roupa oferecer regulagens traz um melhor custo benefício para os pais que poderão utilizar a roupa por mais tempo. E também, como ela é uma peça única, é mais fácil para os cuidadores vestirem a criança, evitando assim que se confundam e façam o seu posicionamento de forma errada. Ela também é a mais ventilada podendo ser utilizada em temperaturas mais elevadas, evitando que a criança se incomode com o uso da roupa.

A proposta final do projeto consiste em um suporte postural biocinético, cujo nome (biocinético) é inspirado no uso deste produto na área da fisioterapia, que possibilitará a criança ter a liberdade de movimentar-se em postura correta. Baseado na biônica da borboleta permite o menor uso de material, visto que é produzido em elástico na cor preta para melhor conservação do produto, além de estar em harmonia com os protetores. E a regulagem observa o conceito de design universal com intuito de trazer maior custo beneficio, atendendo a todo o público alvo, como pode ser visto nas figuras 04 e 05.

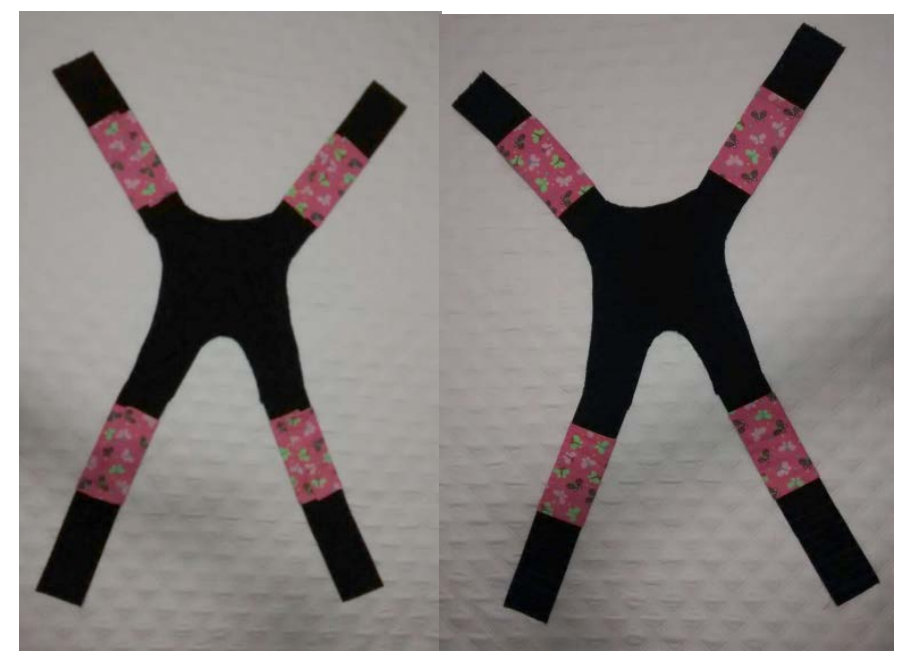

Figura 04: Imagem do produto final com os protetores. 


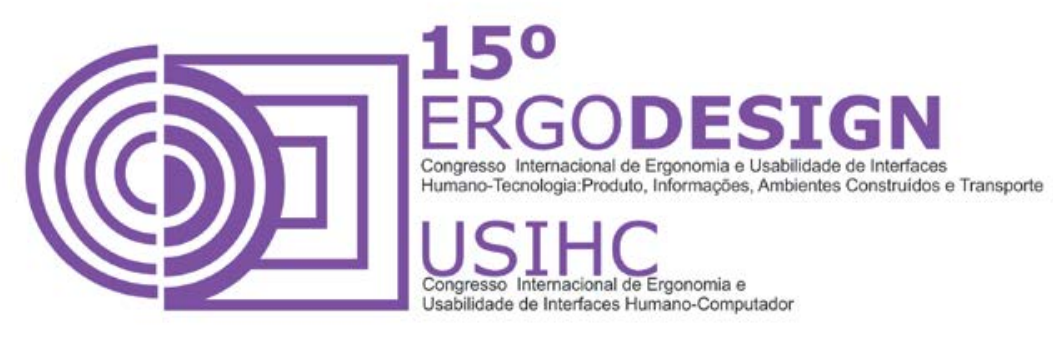

Fonte: Elaborado pelo autor.

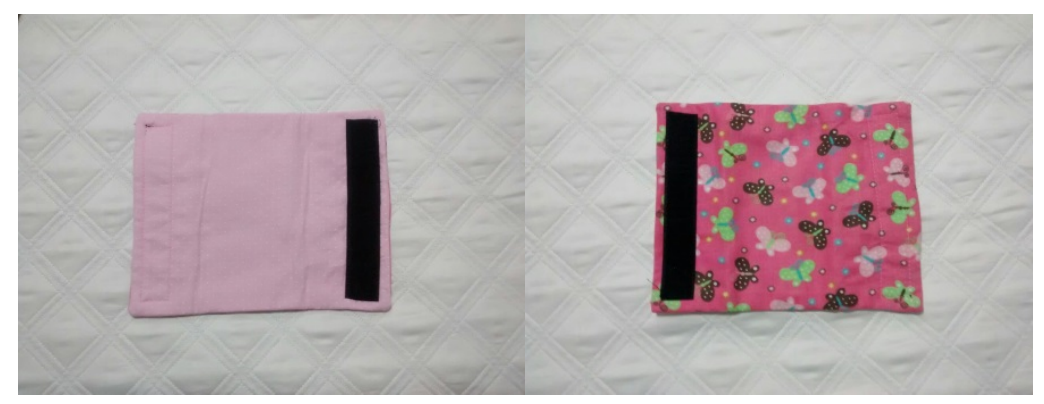

Figura 05: Imagem dos protetores.

Fonte: Elaborado pelo autor.

O suporte postural foi pensado para ser vendido juntamente com mais quatro conjuntos de dois pares de protetores, com estampas diferentes, para que o cuidador ou o terapeuta possa trocálo, para limpeza ou de acordo com a escolha da criança. Sendo que o protetor poderá ser vendido em pares avulsos.

O custo liquido de um suporte postural foi de aproximadamente $R \$ 100,00$, sendo que este custo é de apenas uma peça, assim em produção o valor liquido pode diminuir, deixando, então o produto mais acessível ao público.

\section{DISCUSSÃO}

Como base neste estudo notou-se que a atuação do design em áreas como a da saúde está muito submetida aos seus conhecimentos específicos para que atue no desenvolvimento de soluções inovadoras para beneficiar os usuários destas áreas, a da fisioterapia é uma delas. Isso faz com que a pesquisa e o emprego de materiais, alternativos e mais inteligentes, para as finalidades de uso fiquem restritos ao conhecimento dos profissionais da área que se propõem a desenvolver soluções por si próprios para os problemas que encontram no seu cotidiano de atendimento.

Este fator vai de encontro com o principio de design, enquanto área que desenvolve soluções para gerar qualidade de vida as pessoas e que ao se deparar com produtos como o tratado neste projeto se debruça sobre o problema a fim de conseguir este objetivo. Porém, este é um fator ainda bastante amplo e que se converte em um desafio para o design na busca de inovações que vão beneficiar os usuários da área da saúde.

\section{CONCLUSÃO}

Atualmente o design está presente em tudo que se vê, utiliza e admira. Este trabalho vai além da beleza, do conforto e da facilidade, está em melhorar a qualidade de vida das pessoas, e trazer em pequenas mudanças a realização de atividades que antes pareciam impossíveis. 


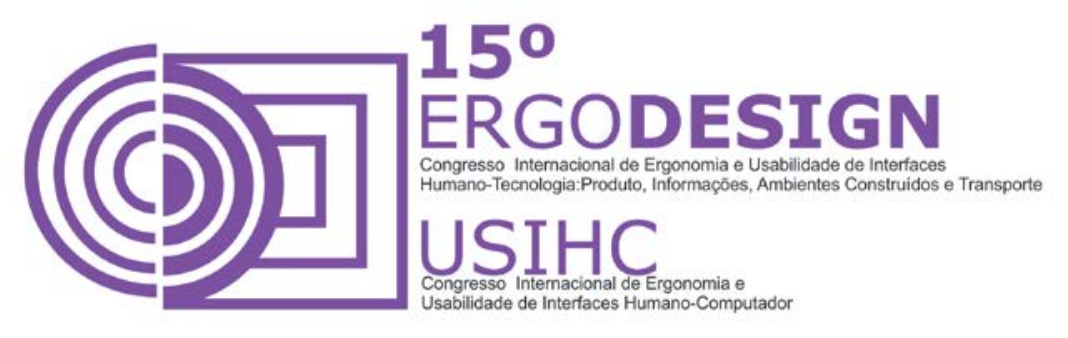

Assim, foi desenvolvida uma alternativa inovadora para oferecer condições de suporte postural biocinético em tratamento fisioterapêutico de crianças com idade entre 2 a 8 anos, com emprego de materiais economicamente mais favoráveis ao consumidor a fim de torna-lo viável ao grande público.

Para isso foram avaliadas marcas e modelos disponíveis no mercado, analisados os pontos positivos e os negativos, comparados à eficácia, materiais e custos. A partir disso foram levantados os requisitos para este projeto, onde puderam ser diagnosticadas as necessidades para a melhoria do traje, e aplicado ao estudo.

O suporte postural biocinético vai atuar melhorando a qualidade de vida de crianças acometidas por patologias neurológicas que geram alterações posturais, possibilitando:

- Melhorar postura em pé e sentada;

- Facilitar o transporte pelos pais;

- Maior integração com o ambiente externo;

- Diminuição das dores causadas por posturas inadequadas;

- Remodelamento ósseo e articular em bebês e crianças;

- Consciência corporal e estabilidade postural;

- Alinhamento articular funcional;

- Além de ser dinâmico, sendo fabricado por um material leve, flexível, respirável, e que pode ser utilizado sob a roupa normal;

- Desenvolver afetividade e, por consequência, aceitabilidade do usuário com o produto, por meio das características lúdicas.

- Ainda assim os estudos devem ser contínuos para que se possa melhorar e aperfeiçoar ainda cada vez mais este produto, a fim de torná-lo popular e sempre mais eficaz.

Este projeto foi uma oportunidade de contribuir com uma necessidade realmente pertinente para a sociedade, mostrando que o design é uma atividade capaz de transformar realidades.

\section{REFERÊNCIAS BIBLIOGRÁFICAS}

ALVES DE OLIVEIRA, A I. Pesquisa e desenvolvimento infantil. Belém: Conhecimento \& Ciência; 2008.

ARIÉS, P. História social da criança e da família. (trad. Dora Flaksman) $2^{\mathrm{a}}$ ed. Rio de Janeiro: Guanabara, 1986.

BEZERRA, M.F; WAECHTER, H. Brincando com a roupa: um estudo sobre a compreensão de elementos lúdicos na moda infantil. In: $8^{\circ}$ Congresso brasileiro de pesquisa e desenvolvimento em design. Anais...São Paulo,2008. Disponível em: < http://www.modavestuario.com/232bricandocomaroupa.pdf>. Acesso em: 22 de out. de 2014.

CRONEY, J. Antropometria para Diseñadores. Barcelona, Gustavo Gili, 1978. 


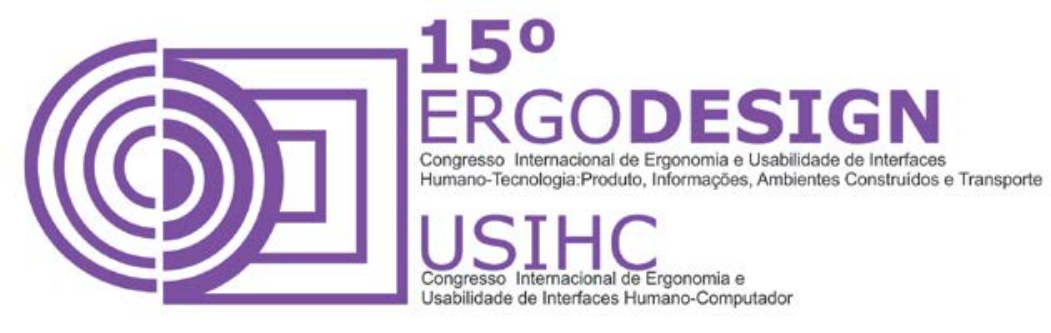

CUNHA, Nylse Helena Silva. Criar para brincar: a sucata como recurso pedagógico: atividades para psicomotricidade. São Paulo: Aquariana, 2007.

FREITAS, Z. C. D.; BORGES, A. A influência das embalagens no comportamento de compra do consumidor infantil. Belo Horizonte: 2006. 17 p. Disponível em: <http://artigocientifico.uol.com.br/uploads/ artc_1162836219_37.pdf>. Acesso em: 25 out. 2014.

HEIRICH, A.P.; TRONCOSO, S.M.K. O uso de elementos lúdicos no vestuário infantil. Gramado: 2014.

HUIZINGA, Johan.Homo Ludens: O jogo como elemento da cultura. São Paulo: Perspectiva, 1971.

IIDA, I. Ergonomia - Projeto e Produção. São Paulo, Edgard Blücher, 1990.

LURIE, A. A linguagem das roupas. Rio de Janeiro: Rocco, 1997. 285p.

MAFRA, S. R. C. O Lúdico e o Desenvolvimento da Criança Deficiente Intelectual, 2008.

MOORE, K.L. Anatomia orientada para clínica. Guanabara koogan - 6ª edição, 2011.

PASCHOARELLI, L. C. O posto de trabalho carteira escolar como objeto de desenvolvimento da educação infantil: uma contribuição do Design e da Ergonomia; Dissertação de Mestrado - Faculdade de Arquitetura, Artes e Comunicação. Bauru: Universidade Estadual Paulista, 1997.

PIAGET, Jean. A formação do símbolo na criança: imitação, jogo e sonho, imagem e representação. [tradução Álvaro Cabral, 1975]. $2^{\mathrm{a}}$ ed. Rio de Janeiro.

PIAGET, Jean. Biologia e Conhecimento. $2^{\mathrm{a}}$ Ed. Vozes: Petrópolis, 1996.

POSTMAN, Neil. O desaparecimento da infância. Tradução de Suzana Menescal de Alencar Carvalho e José Laurenio de Melo. Rio de Janeiro: Graphia, 1999.

SANTANA, S. A. Pedagogias do vestir e moda infantil: contribuições da ZIG-ZIG-ZAA para a alfabetização e para a formação das identidades de gênero, 2011.

SUIT Therapy.TherasuitMethod, 2002. Disponível em: <www.suittherapy.com>. Acesso em: 28 out. 2014

THERATOGS. Disponível em: < http://theratogs.com>. Acesso em: 22 out. 2014

UBALDO, J. O. P. A utilização do método neuroevolutivo Bobath na paralisia cerebral: intervenção fisioterapêutica domiciliar, 2002. 50 f. Trabalho de Conclusão de Curso (Graduação em Fisioterapia)Universidade do Sul de Santa Catarina, Florianópolis, 2002. 